FEDERAL RESERVE BANK of ST. LOUIS

\section{RESEARCH DIVISION} Working Paper Series

\title{
Are Government Spending Multipliers Greater During Periods of Slack? Evidence from 20th Century Historical Data
}

\author{
Michael T. Owyang, \\ Valerie A. Ramey \\ and \\ Sarah Zubairy
}

Working Paper 2013-004A

https://doi.org/10.20955/wp.2013.004

January 2013

\section{FEDERAL RESERVE BANK OF ST. LOUIS \\ Research Division \\ P.O. Box 442}

St. Louis, MO 63166

The views expressed are those of the individual authors and do not necessarily reflect official positions of the Federal Reserve Bank of St. Louis, the Federal Reserve System, or the Board of Governors.

Federal Reserve Bank of St. Louis Working Papers are preliminary materials circulated to stimulate discussion and critical comment. References in publications to Federal Reserve Bank of St. Louis Working Papers (other than an acknowledgment that the writer has had access to unpublished material) should be cleared with the author or authors. 


\title{
Are Government Spending Multipliers Greater During Periods of Slack? Evidence from 20th Century Historical Data*
}

\author{
Michael T. Owyang \\ Valerie A. Ramey \\ Sarah Zubairy
}

January 21, 2013

\begin{abstract}
A key question that has arisen during recent debates is whether government spending multipliers are larger during times when resources are idle. This paper seeks to shed light on this question by analyzing new quarterly historical data covering multiple large wars and depressions in the U.S. and Canada. Using an extension of Ramey's (2011) military news series and Jordà's (2005) method for estimating impulse responses, we find no evidence that multipliers are greater during periods of high unemployment in the U.S. In every case, the estimated multipliers are below unity. We do find some evidence of higher multipliers during periods of slack in Canada, with some multipliers above unity.
\end{abstract}

\section{Introduction}

A key question that has arisen during recent debates is whether government spending multipliers are larger during periods of slack. Some researchers and policy makers have argued that while government spending multipliers are estimated to be modest on average, they might become greater during times when resources are underutilized. Auerbach and Gorodnichenko

${ }^{*}$ This paper was prepared for the American Economic Review Papers and Proceedings. The authors thank Robert Barro and Gordon Liao for use of their Canadian newspaper excerpts, Michelle Alexopoulos for providing us with some of the historical Canadian data, and Alan Blinder for alerting us to a discrepancy in an earlier version of the data. We are also grateful to Òscar Jordà and Garey Ramey for very helpful suggestions and to Kate Vermann for research assistance. The views expressed herein should not be taken to be the official opinions of the Federal Reserve Bank of St. Louis, the Federal Reserve System, or the Bank of Canada. 
(2012a, 2012b) (AG) test this hypothesis and find larger multipliers during recessions in both quarterly post-WWII U.S. data and in annual cross-country panel data since 1985. Their findings suggest multipliers near zero during expansions but between 1.5 to 2 during recessions. Fazzari, Morley, and Panovska (2012) confirm these findings using different methods and measures of slack in U.S. data since 1967. Gordon and Krenn (2010) find that multipliers are larger before mid-1941 than after in their analysis of U.S. data from 1919 to 1953. In addition, numerous cross-state analyses estimate bigger multipliers during periods of slack. On the other hand, Crafts and Mills (2012) analyze government spending multipliers in U.K. data from 1922 to 1938-a period of considerable slack-yet find multipliers between 0.5 to 0.8 .

This paper contributes to this debate by using newly constructed historical data for the U.S. and Canada to examine whether government spending multipliers are larger during periods of significant slack. The fluctuations in government spending and unemployment during the two World Wars and the Great Depression were large, so data from this period are potentially rich sources of information on time variation in government spending multipliers.

In contrast to some of the previous findings, we do not observe higher multipliers during times of slack in the U.S. For Canada, we find evidence for multipliers that are substantially higher during periods of slack in the economy.

\section{Data}

We construct historical data for both the U.S. and Canada on GDP, the GDP deflator, government spending, population, and the unemployment rate. We choose to use quarterly data, which requires interpolation, rather than annual data because agents often react quickly to news. As the online data appendix outlines, we use various higher frequency series to interpolate existing annual series. In addition, we use narrative methods to extend Ramey's (2011) "news" variable reflecting changes in the expected present value of government spending in 
response to military events. We extend the series back in time for the U.S. and construct a preliminary news series for Canada based on events around WWII and the Korean War. Because of data availability, our sample extends from 1890q1 to 2010q4 for the U.S. and from 1921q1 to 2011q4 for Canada.

Our measure of slack is the unemployment rate. For the U.S., we use 6.5 percent as the threshold based on Bernanke's recent announcement about policy (FOMC 2012). This results in one-third of the observations being above the threshold. For Canada, we use 7 percent; even with the higher threshold 50 percent of the observations are above the threshold.

Figures 1 and 2 show the unemployment rate and the military spending news shocks for the two countries. As Figure 1 shows, the largest military spending news shocks are distributed across periods with a variety of unemployment rates in the U.S. For example, the largest news shocks about WWI and the Korean War occurred when the unemployment rate was below 6.5 percent. In contrast, the initial large news shocks about WWII occurred when the unemployment rate was still very high. Formal tests indicate that the news variable has significant explanatory power and high instrument relevance for government spending in the U.S., overall and separately across the two unemployment states.

The Canadian data only extend back to 1921, and thus do not include WWI. Figure 2 shows that the initial large news shocks of WWII occur when the unemployment rate is still elevated, but later ones arrive when the unemployment rate is quite low. All of the Korean War news shocks occur when the unemployment rate is low. Formal tests suggest that the preliminary military news variable for Canada has somewhat lower explanatory power and instrument relevance than for the U.S.

\section{Econometric Method}

Following AG (2012b), we use Jordà's (2005) local projection technique to calculate impulse responses. This method easily accommodates state dependence and does not impose the 
implicit dynamic restrictions involved in VARs.

We estimate a set of regressions for each horizon $h$ as follows:

$$
\begin{aligned}
z_{t+h}= & I_{t-1}\left[\alpha_{A, h}+\psi_{A, h}(L) y_{t-1}+\Omega_{A, h}(L) g_{t-1}+\beta_{A, h} \frac{n e w s_{t}}{Y_{t-1}}\right] \\
& +\left(1-I_{t-1}\right)\left[\alpha_{B, h}+\psi_{B, h}(L) y_{t-1}+\Omega_{B, h}(L) g_{t-1}+\beta_{B, h} \frac{n e w s_{t}}{Y_{t-1}}\right]+\text { quartic trend }+\varepsilon_{t} .
\end{aligned}
$$

$z$ is a function (discussed below) of either real per capita GDP $(Y)$ or government spending $(G), y$ and $g$ are the logs of these variables, and "news" is the change in the expected present value of government spending caused by military events. $h$ is the horizon and the functions of $L$ denote polynomials in the lag operator. $I$ is a dummy variable that takes the value of one when the unemployment rate is above a threshold. We allow all of the coefficients (except those on trend terms) to vary according to whether the unemployment rate is above ("A") or below ("B") the threshold. The shock we identify is to the news variable.

As an illustration of the method, we estimate the two-quarter-ahead impulse response of $z$ by regressing $x_{t+2}$ on the variables on the right hand side of Equation (1). We use the estimate of $\beta_{A, 2}$ for the high unemployment rate state and $\beta_{B, 2}$ for the low unemployment rate state. We estimate separate regressions for output and government spending at each horizon $h$.

The standard way to define the z's is as the logs of real GDP and government spending. However, the calculated impulse response functions do not directly reveal the government spending multiplier because the percent changes must be converted to dollar equivalents. Virtually all analyses using VAR methods obtain the spending multiplier by using an ad hoc conversion factor based on the sample average of $Y / G$. Our investigations reveal that this widely-used method can lead to biases in multiplier estimates. In particular, we find that this method often generates multipliers greater than unity even when auxiliary specifications show 
that private spending falls when government spending increases. This bias occurs because the ratio of $Y / G$ varies greatly over the sample period we consider. Thus, we instead use the variable definitions of Hall (2009) and Barro and Redlick (2011) that convert GDP and government spending changes to the same units. In particular, our $z$ variables are defined as $\left(Y_{t+h}-Y_{t-1}\right) / Y_{t-1}$ and $\left(G_{t+h}-G_{t-1}\right) / Y_{t-1}$. The first variable is approximately equal to $\ln \left(Y_{t+h}\right)-\ln \left(Y_{t-1}\right)$, and hence is analogous to the standard VAR specification. The second variable can be rewritten as:

$$
\begin{aligned}
\frac{G_{t+h}-G_{t-1}}{Y_{t-1}} & =\frac{G_{t+h}-G_{t-1}}{G_{t-1}} \cdot \frac{G_{t-1}}{Y_{t-1}} \\
& \approx\left(\ln G_{t+h}-\ln G_{t-1}\right) \cdot \frac{G_{t-1}}{Y_{t-1}}
\end{aligned}
$$

Thus, this variable converts the percent changes to dollar changes using the value of $G / Y$ at each point in time rather than the average over the entire sample. This means that the coefficients from the $Y$ equations are in the same units as those from the $G$ equations, which is required for constructing multipliers. It would be difficult to perform this variable transformation if we were using standard VAR methods to compute impulse responses; it is easy to do so in the Jordà framework.

\section{Results}

Figure 3 shows the responses of government spending and output to a military news shock in the linear model using the U.S. data. The bands are 95 percent confidence bands and are based on Newey-West standard errors that account for the serial correlation induced in regressions when the horizon, $h>0$. After a shock to news, output and government spending begin to rise and peak at around 12 quarters.

Multipliers are derived from the estimated $\beta_{A, h}$ and $\beta_{B, h}$ from the $Y$ and $G$ equations. 
We compute multipliers over three horizons: as the cumulative responses through two years, four years, and at the peaks of each response. As indicated in the first column of the top panel of Table 1, the implied multipliers are below one and range from 0.7 to 0.9 . These results are consistent with those of Barro and Redlick (2011) and Ramey (2011).

The key question of this paper is whether the linear model masks a higher multiplier during times of slack. Figure 4 shows the responses when we estimate the state-dependent model. Similar to many pre-existing studies (e.g., AG 2012b), we find that output responds more robustly during high unemployment states. However, note that government spending also has a stronger response during those particular states. Consequently, Columns 2 and 3 of Table 1 show that some of the implied multipliers are slightly lower during the high unemployment state in the U.S. data and are always below unity. These results are not due to our particular specification, for we find similar results if we use other unemployment values for the threshold, use a smooth transition threshold model as in AG (2012a, b), or use the standard log variables for the dependent variables. In addition, we find that when we apply the Jordà method to AG's (2012a) post-WWII data, based on either shocks to news or government spending, there is no significant difference in the responses across states. Further investigation is necessary to understand why the Jordà method, used by AG (2012b) on a panel of countries, produces results that are different from the STVAR model used by AG (2012a) on U.S. data.

Figure 5 shows the results for the linear model using the Canadian data. Both government spending and output rise in a sustained manner, though the estimated government spending responses are rather erratic. As the first column of Table 1 shows, the implied multipliers are below unity in the linear model.

Figure 6 shows the results from the state dependent model. The responses of government spending and GDP are not very different for the first two years across states, but then diverge starting in the third year when both government spending and GDP climb significantly in the high unemployment state. 
Table 1 shows that the implied multipliers are greater during periods of slack in Canada. For example, using the multipliers based on the integral through two years, the value is 1.6 when the initial shock hits during the high unemployment state in contrast to only 0.44 when it hits in the low unemployment state. Thus, the Canadian estimates suggest that multipliers are substantially greater in the high unemployment state. The exact values depend on the horizon since the estimated responses tend to be erratic.

\section{Conclusion}

We have investigated the proposition that multipliers are greater during periods of slack using newly constructed historical data for the U.S. and Canada. Using Jordà's (2005) local projection method, a threshold model based on the level of the unemployment rate, shocks to military news, and definitions of variables that obviate the need for ad hoc conversion factors, we find no evidence that multipliers are higher during periods of slack in quarterly U.S. data from 1890 to 2010 . In all states, multipliers appear to be between 0.7 and 0.9 . In contrast, estimates using quarterly Canadian data from 1921 to 2011 indicate that multipliers are typically greater during periods of slack. The multipliers are around 0.5 during the nonslack state, but are above unity during the slack state at many horizons. It is important to point out, though, that because we do not adjust for the fact that taxes often rise at the same time as government spending, these estimated multipliers are not necessarily equal to pure deficit-financed multipliers.

\section{References}

[1] Auerbach, Alan and Yuriy Gorodnichenko. 2012a. "Measuring the Output Responses to Fiscal Policy." American Economic Journal: Economic Policy 4 (2): 1-27. 
[2] Auerbach, Alan and Yuriy Gorodnichenko. 2012b. "Fiscal Multipliers in Recession and Expansion" forthcoming in Fiscal Policy After the Financial Crisis, eds. Alberto Alesina and Francesco Giavazzi, University of Chicago Press.

[3] Barro, Robert J., and Charles J. Redlick. 2011. "Macroeconomic Effects from Government Purchases and Taxes." Quarterly Journal of Economics 126 (1): 51-102.

[4] Crafts, Nicholas and Terence C. Mills. 2012. "Rearmament to the Rescue? New Estimates of the Impact of 'Keynesian' Policies in 1930s' Britain." October Working Paper.

[5] Fazzari, Steven M., James Morley and Irina Panovska. 2012. "State Dependent Effects of Fiscal Policy." Mimeo Australian School of Business.

[6] FOMC. Federal Open Market Committee Statement. December 12, 2012. http://www.federalreserve.gov/newsevents/press/monetary/20121212a.htm

[7] Gordon, Robert J. and Robert Krenn. 2010. "The End of the Great Depression: VAR Insight on the Roles of Monetary and Fiscal Policy." NBER Working Paper 16380, September.

[8] Hall, Robert E. 2009. "By How Much Does GDP Rise If the Government Buys More Output?" Brookings Papers on Economic Activity, 2 (2009): 183-231.

[9] Jordà , Òscar. 2005. "Estimation and Inference of Impulse Responses by Local Projections." American Economic Review 95 (1): 161-82.

[10] Ramey, Valerie A. 2011. "Identifying Government Spending Shocks: It's All in the Timing." Quarterly Journal of Economics 126 (1): 1-50.

[11] Ramey, Valerie A. 2012. "Government Spending and Private Activity." forthcoming in Fiscal Policy After the Financial Crisis, eds. Alberto Alesina and Francesco Giavazzi, University of Chicago Press. 


\section{$6 \quad$ Figures and Tables}

Table 1: Estimated Multipliers

\begin{tabular}{lccc}
\hline & $\begin{array}{c}\text { Linear Model } \\
(1)\end{array}$ & $\begin{array}{c}\text { High Unemployment } \\
(2)\end{array}$ & $\begin{array}{c}\text { Low Unemployment } \\
(3)\end{array}$ \\
\hline U.S. & & & \\
2 Year Integral & 0.72 & 0.76 & 0.72 \\
4 Year Integral & 0.81 & 0.78 & 0.88 \\
Peak & 0.87 & 0.83 & 0.93 \\
Canada & & & \\
2 Year Integral & 0.67 & 1.60 & 0.44 \\
4 Year Integral & 0.79 & 1.16 & 0.46 \\
Peak & 0.57 & 0.65 & 0.49 \\
\hline
\end{tabular}

Note: The integral measures are computed as the ratio of the sum of coefficients from the $Y$ and the $G$ equations. The peak measure is the ratio of the coefficients at their respective peaks. 
Figure 1: U.S. Unemployment and Military Spending News
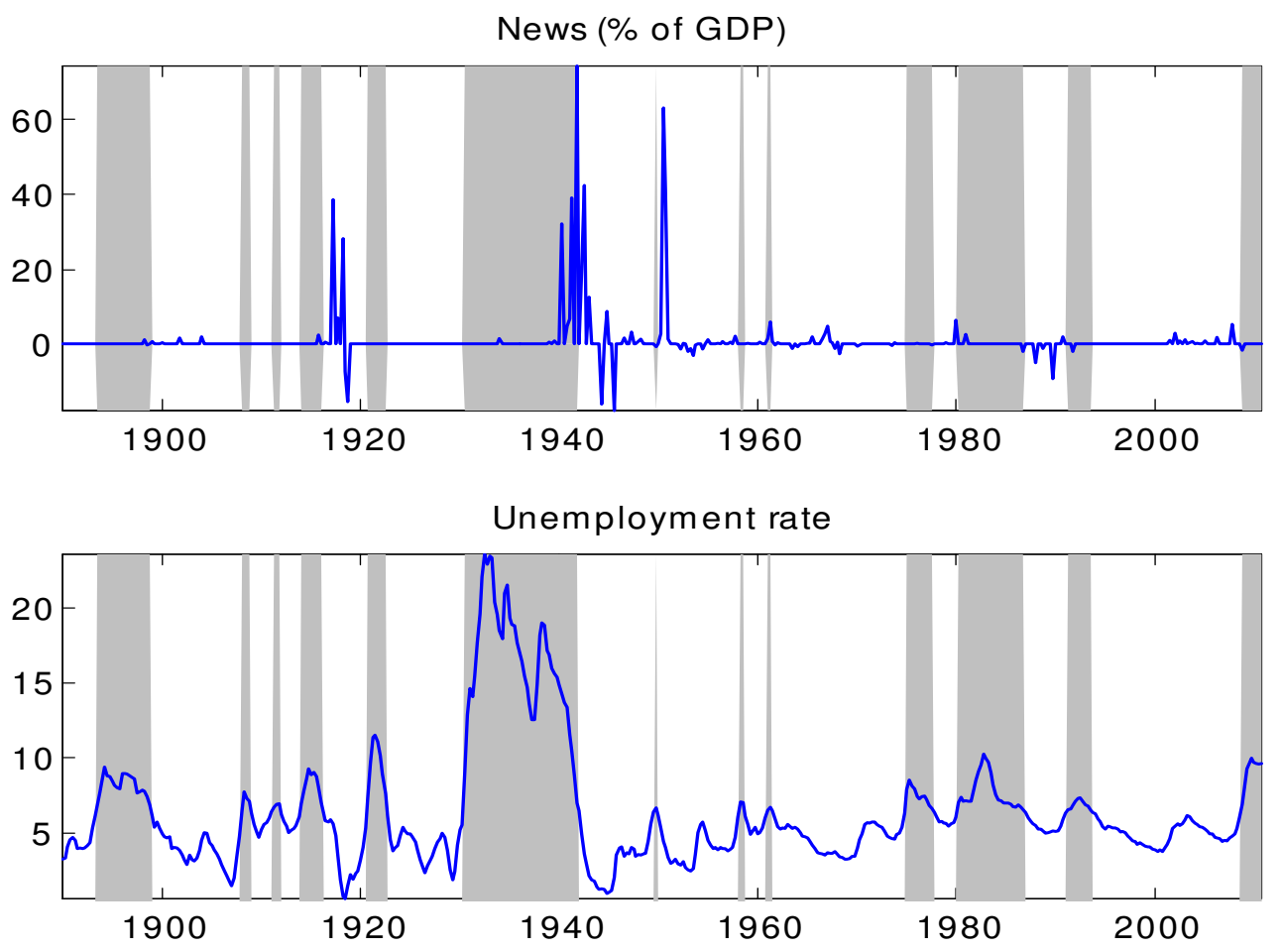

Note: Shaded areas indicate time periods when the unemployment rate is above the threshold. 
Figure 2: Canadian Unemployment and Military Spending News News (\% of GDP)

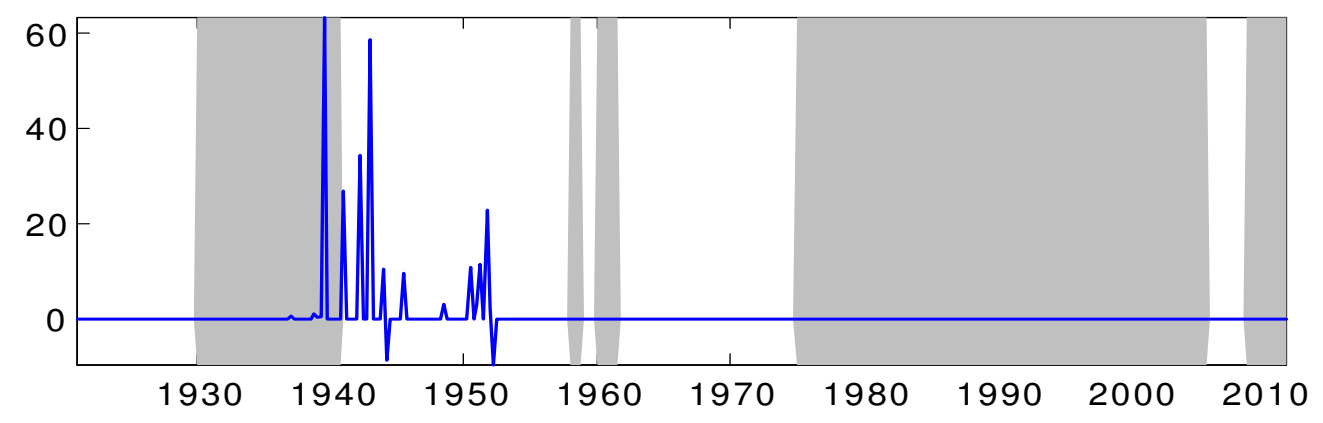

Unemployment rate

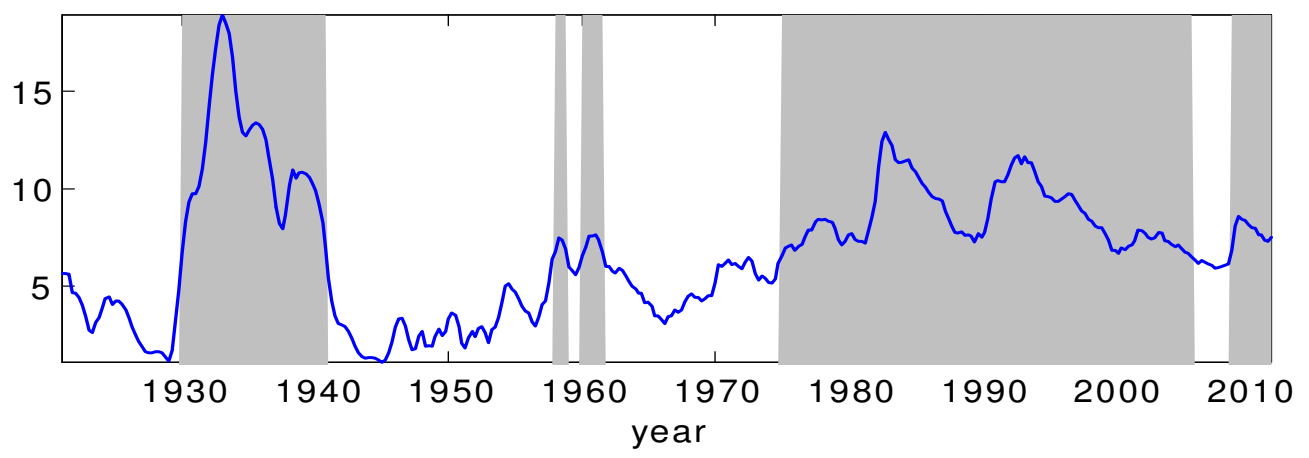

Note: Shaded areas indicate time periods when the unemployment rate is above the threshold. 
Figure 3: U.S. Response of Government Spending and GDP to a News Shock Equal to 1\% of GDP, Linear Model.
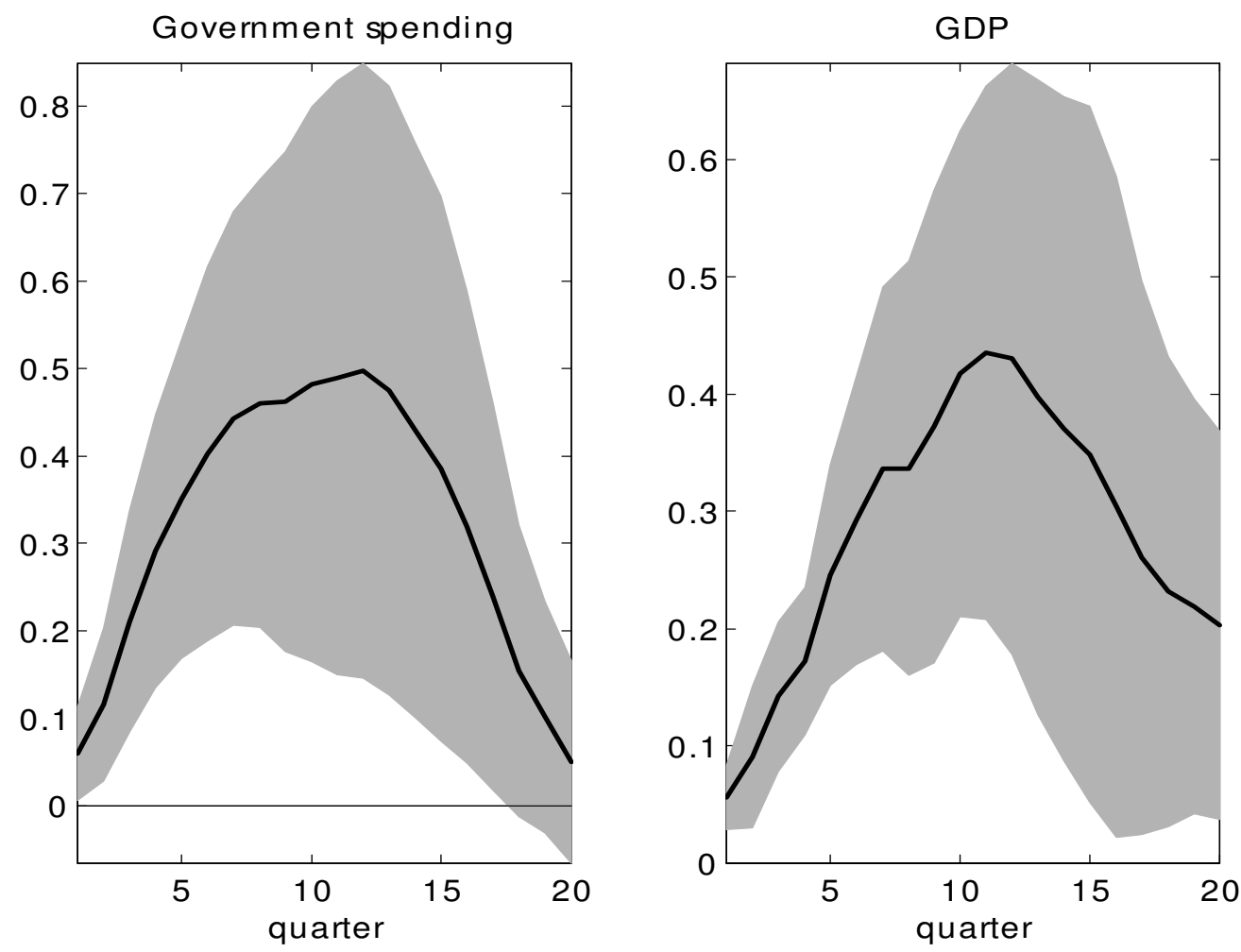

Note: Shaded areas are $95 \%$ confidence intervals. 
Figure 4: U.S. Response of Government Spending and GDP to a News Shock Equal to 1\% of GDP, State-dependent Model.
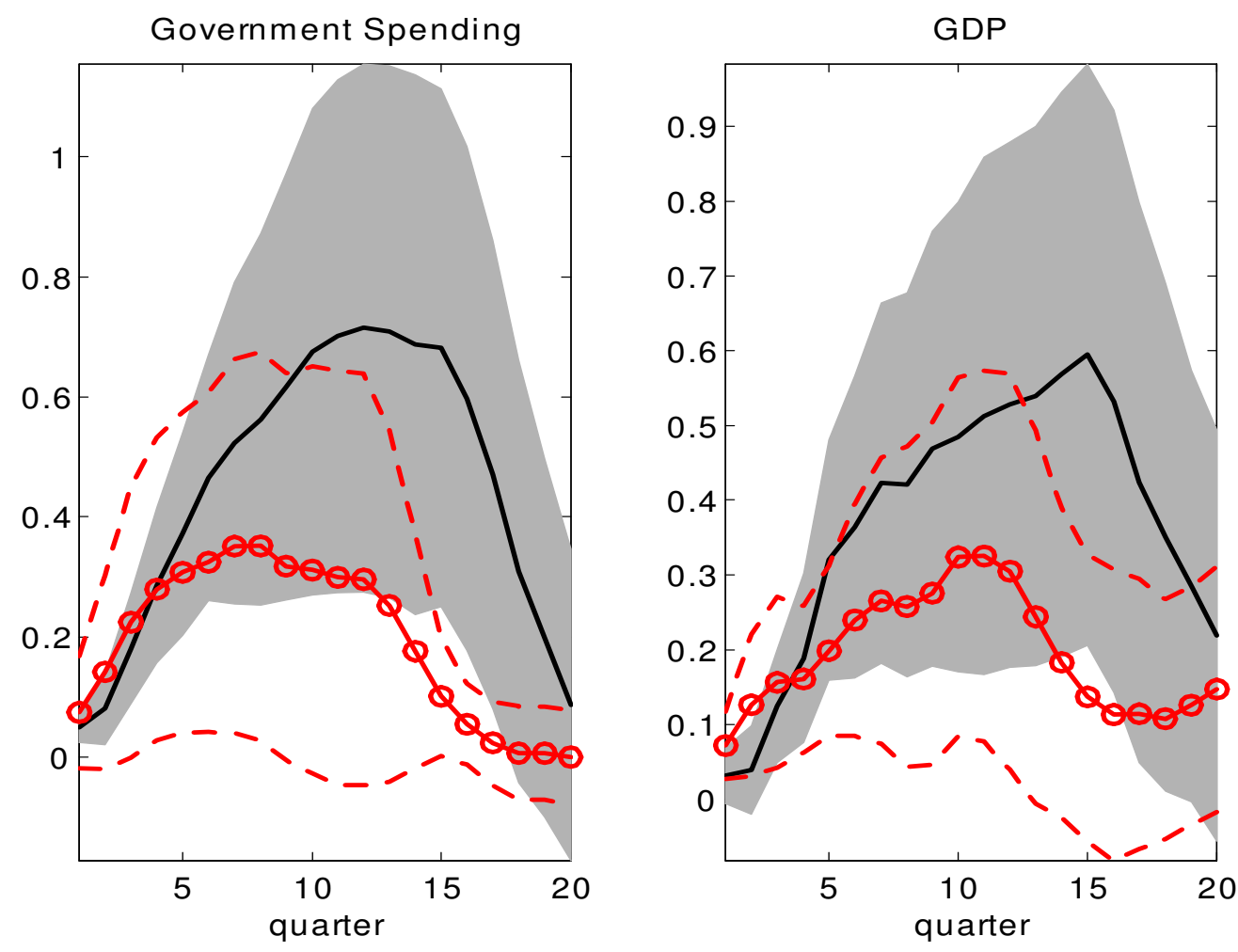

Note: Solid lines are responses in the high unemployment state, lines with circles are responses in the low unemployment state. $95 \%$ confidence intervals are shown. 
Figure 5: Canada Response of Government Spending and GDP to a News Shock Equal to $1 \%$ of GDP, Linear Model.
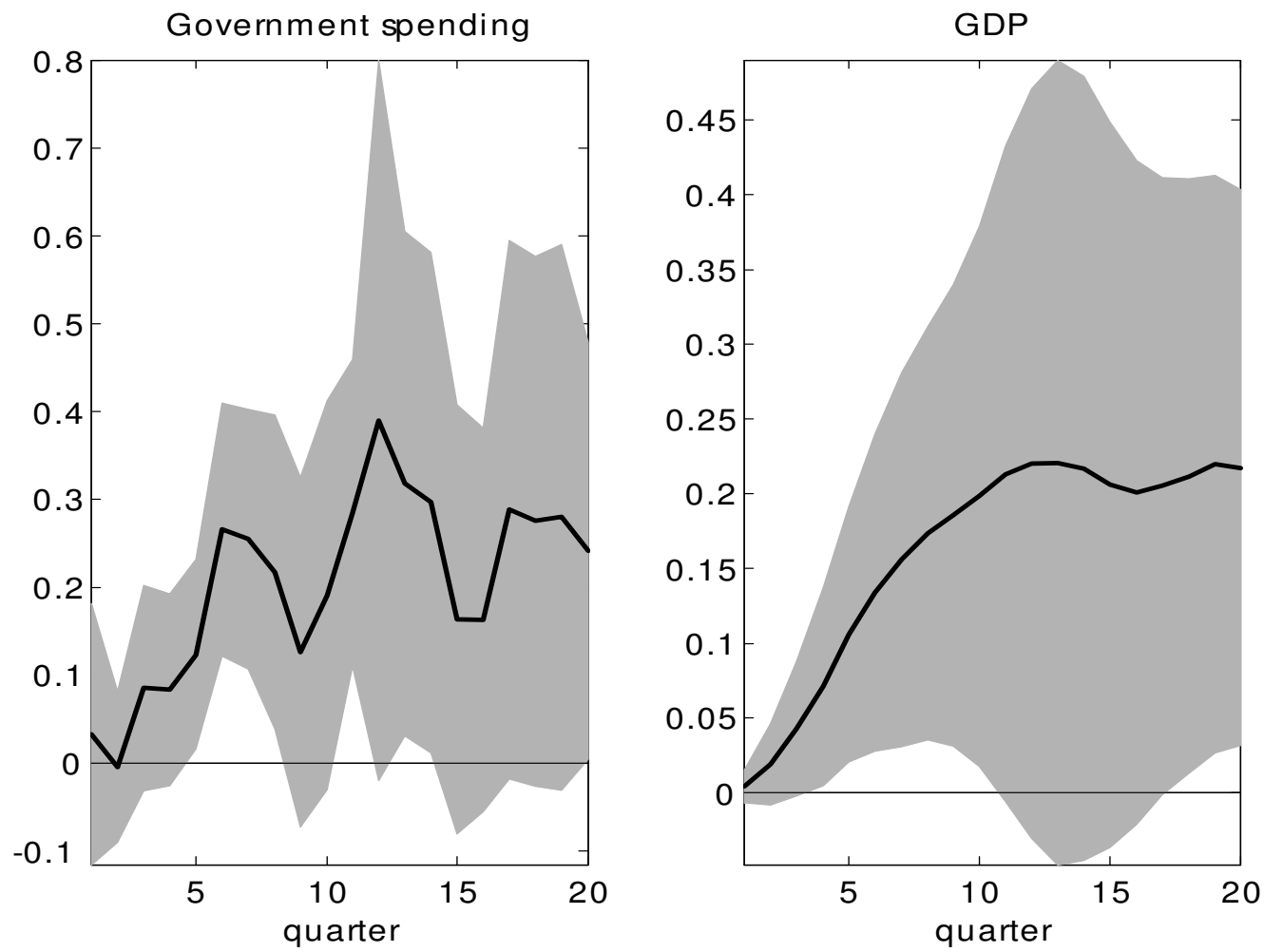

Note: Shaded areas are $95 \%$ confidence intervals. 
Figure 6: Canada Response of Government Spending and GDP to a News Shock Equal to $1 \%$ of GDP, State-dependent Model.
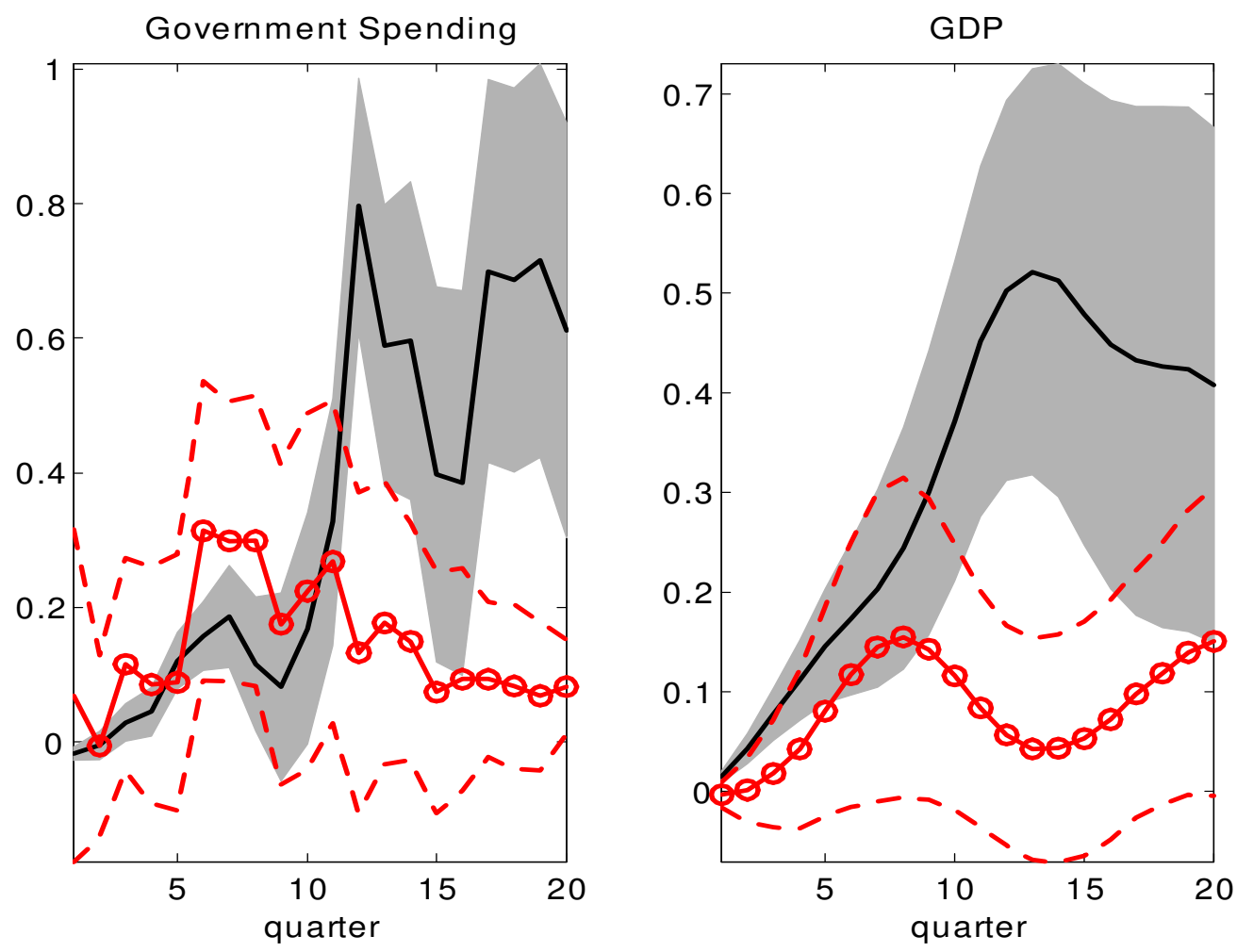

Note: Solid lines are responses in the high unemployment state, lines with circles are responses in the low unemployment state. $95 \%$ confidence intervals are shown. 